\title{
Metal-seramik restorasyonlarda fırınlama sayısı ve seramik kalınlığının renk değişimine etkisi
}

\author{
İlkin Tuncel ${ }^{\alpha}$, Işıl Turp ${ }^{\alpha}$, Buğra Düç ${ }^{\alpha}$, Ahmet Hamdi Selçuker ${ }^{\alpha}$, Akif Aslantaş ${ }^{\alpha}$, Enes Bekman ${ }^{\alpha}$
}

Selcuk Dent J, 2017; 4: 123-127 (Doi: 10.15311/selcukdentj.312779)

Başvuru Tarihi: 17 Mayıs 2017 Yayına Kabul Tarihi: 27 Temmuz 2017

öz

Metal-seramik restorasyonlarda fırınlama sayısı ve seramik kalınlığının renk değişimine etkisi

Amaç: Bu çalışmanın amacı metal alt yapı üzerindeki farklı kalınlık ve markalara ait vener seramiklerin tekrarlayan firınlamalar sonrası renk değişimlerini incelemektir.

Gereç ve Yöntemler: İki farklı markaya ait vener seramik (Vita VMK Master, GC Initial) ile metal altyapı üzerinde iki farklı kalınlıkta (1 ve $1,5 \mathrm{~mm}$ ) örnekler hazırlanmıştır. Her bir grup için örnek sayısı 20 olarak saptanmıştır. Porselen örnekler 2 kez firınlandıktan sonra başlangıç renk ölçümü spektrofotometre ile yapılmıştır. Her örneğin renk ölçümü 3 kez tekrar edilmiş, ortalaması alınarak değerlendirilmiștir. Ölçümler $3,5,7$ ve 9 fırınlama sonrası tekrarlanmıştır ve renk değişim değerleri $(\Delta \mathrm{E})$ elde edilmiştir. Verilerin değerlendirilmesinde tekrarlayan varyans analizi ve grupların karşılaştııılmasında ise Tukey's HSD testi kullanılmışırı.

Bulgular: Seramik kalınlığının $\Delta \mathrm{E}$ değerinde istatistiksel olarak anlamlı farklılık yaratmadığı saptanmıştır. Markalar arasında ise $\Delta \mathrm{E}$ değeri açısından istatistiksel olarak anlamlı farklılık mevcuttur. GC markası grupları bütün fırınlama döngüleri sonrasında Vita markası gruplarına göre daha fazla renk değişimi göstermiştir. Fırınlama sayısının artmasıyla birlikte örneklerin renk değişimi istatistiksel olarak anlamlı derecede artmıştır.

Sonuç: Tekrarlayan fırınlama işlemleri seramiğin renk stabilitesini etkilemektedir ve bu etki markalar arasında farklılıklar gösterebilmektedir.

\section{ANAHTAR KELIMELER}

Kalınlık, metal-seramik restorasyon, renk değişimi, tekrarlayan fırınlama

Dental feldspatik seramikler üstün estetik, kimyasal stabilite ve biyouyumluk özelliklerine rağmen düşük gerilme dayanımına ve kırılgan bir yapıya sahiptirler. ${ }^{1}$ Kırılgan özellikleri ve dayanım değerlerinin düşük olması nedeniyle güçlendirilmeleri gerekmektedir.,3 Metal alt yapı ile beraber kullanımı da bu yöntemlerden biridir. Metal-seramik restorasyonlar diş eksikliğinin fonksiyonel, biyolojik ve estetik olarak giderilmesinde yıllardır kullanılan güvenilir bir metoddur.

Olumlu özelliklerinin yanı sıra metal-seramik restorasyonların çeşitli olumsuz özellikleri de mevcuttur.

\section{ABSTRACT}

The effect of firing number and ceramic thickness on colour change of metal-ceramic restorations

Background: The aim of the study was to evaluate color change of metal supported ceramics of different thicknesses and brands after repeated firings.

Methods: Veneer ceramic specimens on metal substructures were prepared from two different brands (Vita VMK Master, GC Initial)with two different thicknesses (1-1,5 mm). Each group contained 20 specimens. The veneer ceramic was fired for two times and then the initial colour measurement was performed with spectrophotometer. Each specimen was measured for 3 times and their mean was taken. Color measurements were repeated after 3, 5, 7 and 9 firings and color change $(\Delta \mathrm{E})$ values were estimated. The obtained data was analyzed with repeated analysis of variance and the comparisons between the groups were carried out with Tukey's HSD test.

Results: The ceramic thickness did not cause any statistically significant $\Delta \mathrm{E}$ value. However the $\Delta \mathrm{E}$ values between the brands were statistically significant; groups of GC displayed higher $\Delta \mathrm{E}$ values after all firing cycles compared with groups of Vita. The $\Delta E$ values increased significantly with the increase of number of firings.

Conclusion: Repeated firings affect the color stability of the ceramics and this effect varies between brands.

\section{KEYWORDS}

Thickness, metal-ceramic restoration, color change, repeated firings

Bunlar arasında özellikle ince fenotipte dişeti varlığında metal renginin diş etinden yansıması; özellikle kıymetsiz metal alaşımı kullanıldığında görülebilen metal alerjisi; kıymetsiz metal alaşımlarının korozyona yatkınlığı ve metal alt yapının ışığı geçirmemesi sonucu ışık geçirgenliğinin doğal dişlerden farklı olması sayılabilmektedir. Alt yapının metalik rengini kapatabilmek için öncelikle metalin üzerine opak seramik uygulamak gerekmektedir. Opak tabaka üzerine uygulanan seramiğin doğal dişin görsel özelliklerini verebilmesi için uygun kalınlıkta olması restorasyonun estetiği için önemlidir.

\footnotetext{
${ }^{\alpha}$ Bezmialem Vakıf Üniversitesi Diş Hekimliği Fakültesi Protetik Diş Tedavisi Anabilim Dalı, İstanbul
} 
Bununla beraber uygun renk seçimi de estetik bir restorasyonun hazırlanmasında önemli bir faktördür.4 Algılanan diş rengi dentin ve mine içerisinden gelen ve mine yüzeyinden yansıyan ışığın sonucudur. ${ }^{4}$ Yapılacak olan dental restorasyonda renk uyumunun sağlanması için kullanılan seramiğin dentin ve mineye yakın görsel özellikler göstermesi beklenir. Seramiğin rengini etkileyen faktörlerin translusentlik özelliği, yüzey özellikleri ve şekli4,porselenin içeriğ $i^{5-7}$, porselen kalınlığı ${ }^{8}$, final fırınlama $|S ı s|^{9-12}$, porselen yığım tekniğive fırınlama sayıs $\left.\right|^{4,12-13}$ olduğu bildirilmiştir.

Porselen içeriği de rengi etkileyen faktörlerden biridir ve piyasada çeşitli içeriklere sahip porselenler bulunmaktadır. $\mathrm{Bu}$ içerik farklılığı bazen tekrarlayan fırınlanmaların gerektiği metal-seramik restorasyonların renklerinde gözle algılanabilecek miktarlarda değişikliğe yol açabilmektedir. Bu nedenle çalışmamızda Türkiye'de en yaygın kullanılan iki vener seramik markasının farklı kalınlık ve tekrarlayan fırınlama işlemleri sonrasında renk değişimlerinin değerlendirilmesi amaçlanmıştır. Sıfır hipotezi kalınlığın ve tekrarlayan fırınlamaların iki vener seramikte de renk değişimi üzerine etkisi olmadığıdır.

\section{GEREÇ VE YÖNTEM}

Çalışmamızda vener seramik yüklemesinin yapılması için $15 \mathrm{~mm}$ çapında $2 \mathrm{~mm}$ kalınlığında daire şeklinde 60 adet Cr-Co alaşımından (Wirobond, Bego, Germany) metal altyapı hazırlandı. Metal alt yapıların oluşturulması için içerisi mum ile doldurulabilecek kalıplar oluşturuldu. Bu kalıplarla elde edilen mum modelaj revetmana (Bellasum, Bego, Germany) alınarak döküm işlemi firma önerileri doğrultusunda gerçekleştirildi. Döküm işlemi sonrası elde edilen metal altyapılar revetmandan temizlendi, yüzey çapakları giderilerek cila işlemi uygulandı. Hazırlanan metal örneklerin üst yüzeyi $250 \mu \mathrm{m}$ partikül boyutundaki temiz alüminyum oksit ile kumlama işlemine tabi tutuldu.

Vener seramiklerin metal altyapılar üzerine yığımı öncesinde her bir marka grubuna kendi firmasının ürettiği opak seramik (VITA VMK OPAQUE A2, GC Initial MC Paste Opaque OA2) uygulandı. Hazırlanan metal altyapılar üzerine A2 renkte iki farklı kalınlıkta $(1 \mathrm{~mm}$ ve $1,5 \mathrm{~mm}$ ) iki farklı seramik markası (Vita VMK Master (VITA Zahnfabrik, Bad Säckingen, Germany) ve GC Initial (GC Corp, Tokyo, Japan)) yığıldı (Şekil 1). Çalışmamızda klinik kullanımda en çok tercih edilen renklerden biri olması sebebiyle A2 renkte opak ve dentin seramiği tercih edilmiştir. Vener seramiklerin hazırlanmasını standardize etmek amacıyla 10 $\mathrm{mm}$ genişliğinde ve 1 ile 1,5 mm derinliğinde delikleri olan metal şablonlar hazırlandı. Bu kalıplar yardımıyla örnekler üzerine seramikler yığılarak fırınlandı. Opak seramiklerin uygulanması sırasındaki gibi vener seramiklerin metal alt yapıların üzerine yığılması sırasında da firmaların ürünleri için önermiş oldukları fırınlama prosedürleri uygulandı (Tablo 1). Seramikte meydana gelen büzülmeyi kompanse etmek ve seramik miktarının istenilen boyutlarda olmasını sağlamak için büzülen seramik üzerine metal şablon içerisinde tekrar seramik yığıldı ve fırınlama işlemi tekralandı. Vener seramiklerin ilk iki fırınlama işleminden sonra örnek kalınlıkları kumpas (Precimeter S, Renfert GmbH, Hilzingen, Germany) ile 5 farklı noktadan ölçülerek kontrol edildi.

\section{Tablo 1.}

\section{Seramiklerin fırınlama prosedürleri}

\begin{tabular}{lccccc} 
Gruplar & $\begin{array}{c}\text { Ön Isıtma } \\
\text { Derecesi }\end{array}$ & $\begin{array}{c}\text { Kurutma } \\
\text { Zamanı }\end{array}$ & $\begin{array}{c}\text { Sıcaklık } \\
\text { Artışı }\end{array}$ & $\begin{array}{c}\text { Final } \\
\text { Isısı }\end{array}$ & $\begin{array}{c}\text { Final } \\
\text { Isısı } \\
\text { Süresi }\end{array}$ \\
\hline GC & Firing $580^{\circ} \mathrm{C}$ & $6 \mathrm{~min}$ & $55^{\circ} \mathrm{C} / \mathrm{min}$ & $890^{\circ} \mathrm{C}$ & $1 \mathrm{~min}$ \\
\hline Vita & $500^{\circ} \mathrm{C}$ & 7,49 & $55^{\circ} \mathrm{C} / \mathrm{min}$ & 930 & $1 \mathrm{~min}$ \\
\hline
\end{tabular}

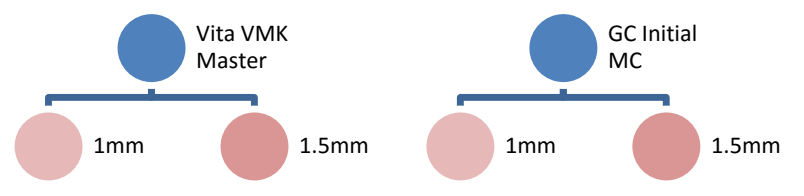

Şekil 1.

Seramik grupları ve alt gruplar

İlk iki fırınlama işlemi örnekler için başlangıç olarak kabul edildi ve her örnek için fırınlama işlemi ilk iki fırınlama sonrasından 9 fırınlamaya kadar tekrar edildi. Örneklerin başlangıç, 3., 5., 7. ve 9. tekrarlanan fırınlama işlemleri sonrasında spektrofotometre (VITA Easyshade Compact, Bad Sackingen, Germany) ile renk ölçümleri yapıldı. Bu sistemle D65 illuminant ışık (renk sıcaklığı 6500 Kelvin olan gün ışığı) ve maksimum iki derecelik sapma açısı göstercek şekilde örneklerin renk ölçümleri yapıldı ve renk değerleri elde edildi. CIE $L^{*} a{ }^{*} b^{\star}$ değerleri herbir örnek için 3'er kez tekrar edildi ve $L^{\star} a^{*} b^{\star}$ değerleri kaydedildi. Bu üç ölçümden elde edilen değerlerin ortalamaları $\Delta \mathrm{E}$ hesaplamalarında kullanıldı. Cihaz kalibrasyonu her grup ölçümü bitiminde değerlendirildi ve yeniden kalibrasyon yapıldı.

CIE $L^{*} a * b *$ ölçümleri ile her örneğin renk değişimi değerlendirildi. Toplam renk değişimi aşağıdaki formül kullanılarak hesaplandı;

$\Delta \mathrm{E}^{\star}=\left[\left(\Delta \mathrm{L}^{\star}\right)^{2}+\left(\Delta \mathrm{a}^{*}\right)^{2}+\left(\Delta \mathrm{b}^{*}\right) 2\right]^{1 / 2}$

Bu formüldeki $\Delta E$ değeri iki renk arasındaki $L^{*} a^{*} b^{\star}$ değerleri arasındaki sayısal farklıığı göstermektedir. $\Delta \mathrm{E}$ değeri 1'den küçük ise iki renk arasındaki 
farklılık algılanamamaktadır. $\Delta \mathrm{E}$ değeri 1 'den büyük ve 3.7 'den küçük ise iki renk arasındaki farklılık bireyin görsel yetisine bağı olarak algılanabilmektedir. $\Delta \mathrm{E}$ değeri 3.7'den büyük ise iki renk arasındaki farklılık algılabilir ve klinik olarak kabul edilemez seviyededir. ${ }^{14,15}$

Elde edilen verilerin istatistiksel analizi SPSS programı (SPSS PC, Vers.10.0; SPSS, Chicago, III) kullanılarak hesaplandı. Verilerin istatistiksel değerlendirilmesinde tekrarlayan varyans analiz ölçümü kullanıldı. İkili karşılaştırmalarda Tukey's HSD testi ve paired 2-tailed testi kullanıldı ( $\alpha=05)$.

\section{BULGULAR}

Çalışma verileri sonucunda en az renk değişiminin $1 \mathrm{~mm}$ kalınlığında Vita seramiğinde olduğu, en yüksek renk değişiminin ise $1,5 \mathrm{~mm}$ kalınlığındaki GC seramiğinde olduğu görüldü. Fırınlama sayıları arasında değerlendirme yapıldığında başlangıç, 3., 5., 7. ve 9. firınlamalar arasında istatistiksel olarak anlamlı farklıı saptandı. Fırınlama sayısının artmasıyla birlikte renk değişiminin de arttığı gözlendi. Kalınlık değişimleri değerlendirildiğinde istatistiksel olarak farklılık gözlenmedi (Tablo 2, Şekil 2).

\section{Tablo 2.}

\section{Grupların renk değişim değerleri ve standart sapmaları}

\begin{tabular}{|lcccc|}
\hline \multicolumn{1}{|c}{ Grup } & 3. Fırınlama & 5. Fırınlama & 7. Fırınlama & 9. Fırınlama \\
\hline $1 \mathrm{~mm}$ GC & $5.01 \pm 1.08 \mathrm{~A}, \mathrm{a}$ & $6.60 \pm 1.21 \mathrm{~A}, \mathrm{~b}$ & $7.83 \pm 1.45 \mathrm{~A}, \mathrm{c}$ & $9.15 \pm 1.27 \mathrm{~A}, \mathrm{~d}$ \\
\hline $1.5 \mathrm{~mm}$ GC & $4.52 \pm 0.82 \mathrm{~A}, \mathrm{a}$ & $6.92 \pm 1.04 \mathrm{~A}, \mathrm{~b}$ & $8.39 \pm 1.01 \mathrm{~A}, \mathrm{c}$ & $9.89 \pm 1.22 \mathrm{~A}, \mathrm{~d}$ \\
\hline $1 \mathrm{~mm}$ Vita & $1.45 \pm 0.54 \mathrm{~B}, \mathrm{a}$ & $2.06 \pm 0,69 \mathrm{~B}, \mathrm{~b}$ & $2.51 \pm 0.78 \mathrm{~B}, \mathrm{c}$ & $2.63 \pm 0,76 \mathrm{~B}, \mathrm{~d}$ \\
\hline $1.5 \mathrm{~mm}$ Vita & $1.20 \pm 0.49 \mathrm{~B}, \mathrm{a}$ & $2.39 \pm 1.19 \mathrm{~B}, \mathrm{~b}$ & $2.77 \pm 1,28 \mathrm{~B}, \mathrm{C}$ & $2.87 \pm 1.27 \mathrm{~B}, \mathrm{~d}$ \\
\hline
\end{tabular}

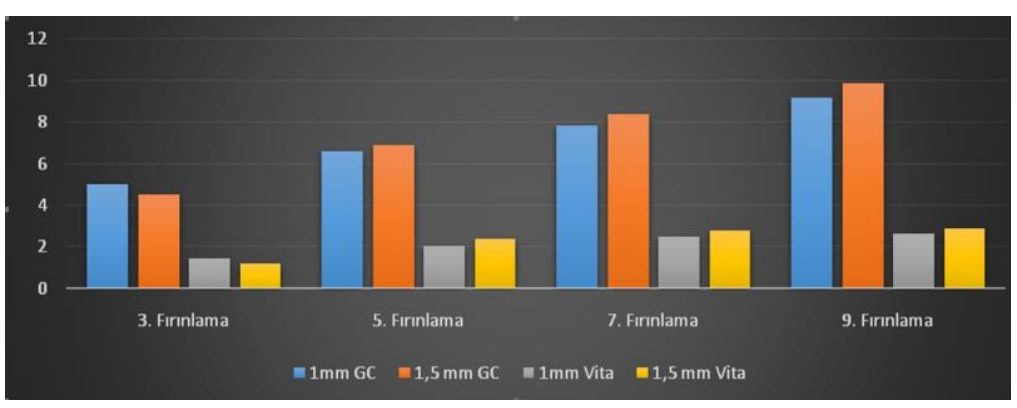

Şekil 2.

Grupların renk değişim değerleri

Markalar arasında renk değişimi açısından istatistiksel olarak anlamlı farklılık bulundu. GC marka grupların bütün sikluslarda Vita marka gruplarına göre daha fazla renk değişimi gösterdiği gözlendi. GC marka gruplar başlangıçtan itibaren klinik olarak kabul edilemeyecek değerlerde $(\geq 3.7 \quad \Delta \mathrm{E})$ renk değişimi gösterirken Vita marka grupların renk değişimi 9. fırınlama sonrasında bile klinik olarak kabul edilebilecek seviyedeydi.

\section{TARTIŞMA}

Çalışma verileri veneer seramiklerin tekrarlayan fırınlama işlemleri sırasında renk değişimi gösterdiğini ve farklı firmaların ürettiği seramik materyalleri arasında istatistiksel olarak anlamlı farklılık bulunduğunu göstermiştir ( $p<0.05)$.

Porselen kalınlığının renk değişimi üzerine etkilerinin de değerlendirildiği çalışmamızda 1 ve 1,5 mm'lik iki farklı kalınlık değerlendirilmiştir. Bazı çalışmalar kalınlığın renk üzerinde etkili olabileceğini rapor etmektedir. ${ }^{16,17} \mathrm{Bu}$ çalışmalarda 0.5 ile $2 \mathrm{~mm}$ arasındaki seramik kalınlıkları değerlendirilmiştir. Kalınlığın renk değişimini etkilediği çalışmalarda kalınlığın artmasıyla birlikte tekrarlanan fırınlama işlemlerinin seramik üzerinde daha az renk değişimi gösterdiğini raporlamışlardır. Çalışmamızın sonucunda seramik kalınlığındaki artış ile (3. fırınlama dışında) birlikte seramikteki renk değişiminin de arttığı bulunmuştur. Fakat kalınlığının tekrarlanan fırınlama işlemleri sonrasında seramik üzerinde istatistiksel olarak önemli bir renk değişimi etkisi olmadığı da görülmüştür.

Markalar kendi aralarında değerlendirildiğinde ise gruplar arasında istatistiksel olarak farklılık bulunmuştur. Markalar arasındaki bu farklılık içerik ve firmaların belirtmiş oldukları fırınlama işlemleri sonucunda ortaya çıkmış olabilir. ${ }^{5}$

Çalışmamızda örneklerdeki renk değişimlerinin araştırımasının yanısıra bu renk değişimlerinin görsel olarak algılanabilirliği de değerlendirilmiştir. Çalışmalarda $\Delta \mathrm{E}$ değerindeki değişikliğin gözle farkedilebildiği değerler farklı kriterlerde değerlendirilmiştir. $\Delta \mathrm{E}$ değerinin 1 'den küçük olduğunda renk farklılı̆ı gözle algılanmaz iken 1-2 arasındaki $\Delta \mathrm{E}$ değerleri bir çok gözlemci tarafından algılanabilir olarak bulunmuştur. $\Delta \mathrm{E}$ değerlerinin 2'nin üzerine çıktığı durumlarda ise renk değişikliğinin açıkça alıgılanabildiği kabul edilmiştir. ${ }^{18}$ Bunun yanı sıra Seghi ve arkadaşları renk değişiminin klinik olarak kabul edilebilir değerini $3,7 \quad \Delta \mathrm{E}$ olarak belirtilmiştir. ${ }^{18}$ İnsan gözünün algılayabildiği renk değişiminin incelendiği başka bir çalışmada ise $\Delta \mathrm{E}$ değerinin üç ve üzeri olduğu durumlarda insan gözünün renk değişikliğini algıladığı bildirilmiştir. ${ }^{19} \quad$ Çalışmamızda tekrarlanan fırınlama işlemleriyle birlikte $\Delta \mathrm{E}$ değeri 1,2 ile 9,88 arasında değişiklik göstermiştir. 
Vita markaya ait $1 \mathrm{~mm}$ ve $1,5 \mathrm{~mm}$ kalınlıktaki gruplar 9 . fırınlama işleminden sonra sırasıyla 2,62 ve 2,86 $\Delta \mathrm{E}^{\prime}$ lik değerleri ortaya koymuştur. Bu değerler hem Seghi ve ark.'ın belirtmiş oldukları 3,7 $\Delta \mathrm{E}^{\prime}$ lik farkın hem de Yap ve ark.'ın belirtmiş olduğu $3 \Delta \mathrm{E}$ 'lik farkın altında kalarak Vita markasının her iki kalınlık değeri için de 9. fırınlama sonrasında bile klinik olarak kabul edilebilir olduğunu göstermiştir. GC markasında ise her iki kalınlık değeri için de 3. fırınlama işleminden sonra bile yapılan değerlendirmelerinde hem Seghi ve ark.'ın hem de Yap ve ark.'ın belirttikleri klinik kabul edilebilirlik değerinin üstünde $\Delta \mathrm{E}$ değeri gözlenmiştir.

CIE renk sistemi $L^{*}, a^{*}, b^{*}$ değerleri olmak üzere 3 farklı eksende renk sistemini tanımlamıştır. $L^{*}$ koordinatı rengin açıklık/koyuluk, parlaklık ve siyah/beyaz karakterini belirtmektedir. Saf siyah 0 , saf beyaz ise $100 L^{*}$ değerini almaktadır. Açık renkteki cisimler daha yüksek $L^{*}$ değerine sahipken, koyu renkteki cisimlerin $L^{*}$ değerleri daha düşüktür. Renk bileşenleri olan $a^{*}$ ve $b^{*}$ koordinatları rengin kromatik karakterini göstermektedir. $a^{*}$ değeri rengin kırmızılık-yeşillilik oranını, b* değeri ise sarılık-mavilik oranını göstermektedir. a* değeri pozitif ise kırmızılığı, negatif ise yeşilliği; $b^{*}$ değeri pozitif ise sarılığı, negatif ise maviliği belirtmektedir. ${ }^{20}$

$L^{*}, a^{*}$ ve $b^{*}$ değerleri tek tek incelendiğinde bütün örneklerin $L^{*}$ değerlerinde fırınlama sayısının artmasıyla birlikte yükselme görülürken $a^{*}$ ve $b^{*}$ değerlerinde azalma görülmüştür. Böylelikle bütün örneklerde $a$ değerinin azalmasıyla birlikte yeşile, $b^{*}$ değerinin azalmasıyla birlikte maviye yaklaşan renk değişimi bulunmuştur.

Seramiklerin rengi metal oksitlerden oluşan renklendirici pigmentler kullanılarak elde edilmektedir. Stabil olmayan bu metal oksitler fırınlama derecelerinde yıkıma uğrayabilirler ve renk değişimine neden olabilirler. $5,13,21,22$ Crispin et $a^{22}$ ve Lund and Piotrowski ${ }^{13}$ sarı ve turuncu renk ajanlarının fırınlama ısılarında en düşük renk stabilitesine sahip olan pigmentler olduklarını bildirmişlerdir. Çalışmamızdaki örneklerin $a^{*}$ ve $b^{*}$ değerindeki azalma renklendirici pigmentlerin fırınlama ısılarındaki yıkımı sonucunda gerçekleşmiş olabilir. ${ }^{5}$ Seramiğin tekrarlanan fırınlama işlemleri sırasında yapı içerisindeki kristal odaklarının oluşması ve oluşan odakların tekrarlanan fırınlama işlemleriyle büyümesi sonucunda yapının ışık geçirgenliğinde azalma olduğu rapor edilmiştir. ${ }^{23,24}$ Çalışmamızda $L^{*}$ değerlerindeki artış seramiğin tekrarlayan fırınlama işlemleri sonrası kristalizasyonundaki artış ve opaklaşması sonucu ortaya çıkmış olabilir.

Çalışmamızın sınırlamaları arasında renk ölçümlerinin sadece spektrofotometre ile yapılması sayılabilir. Spektrofotometreler standardize ışık kaynağının bozulması veya ölçüm yapan aletin diş ve restorasyon üzerinde yanlış konumlandırılması sonucunda değişkenlik gösteren değerler verebilir. ${ }^{25}$ Böylece materyale giren ışığın önemli derecede kırılması veya kaybı olabilir. Bu durum prob ucundan çıkan ışığı veya prob ucuna geri dönen ışığın algılanmasını etkileyebilir. ${ }^{26}$ "Edge-loss" olarak tanımlanan bu ışık kaybı renk ölçümünde hatalara neden olabilir. ${ }^{26-28}$ Kayıp özellikle translusent olan ve ölçüm yapılacak yüzey genişliği spektrofotometre prob genişliğinden küçük olan örneklerde görülür. ${ }^{27,28}$ Çalışmamızda da kullanılan örneklerin translusentlik özellikleri vardır. Bu nedenle gelecek çalışmalarda örneklerin hem spektrofotometre ve hem de kolormetre ile değerlendirilmesi yöntemin verifikasyonunu sağlayacaktır. Çalışmanın bir diğer sınırlaması olarak ise sadece iki marka ve bu markalara ait tek bir rengin kullanılmasıdır. Gelecek çalışmalarda daha fazla renk ve markanın değerlendirilmesi seramiğin laboratuvar ve klinik uygulamalarını daha öngörülebilir kılacaktır.

\section{SONUÇ}

Tekrarlanan fırınlama işlemleri metal-seramik restorasyonlarda renk değişimine neden olmaktadır.

Seramik kalınlığı tekrarlanan fırınlamalar sonrası renk değişimini etkilememektedir.

Seramik markası tekrarlanan fırınlamalar sonrası renk değişimini etkilemektedir. 


\section{KAYNAKLAR}

1. Joiner A. Tooth colour: a review of the literature. J Dent 2004; 32(1): 3-12.

2. McLean JW, Odont D. Evolution of dental ceramics in the twentieth century. J Prosthet Dent 2001; 85: 61-5.

3. McLean JW. The Strengthening of Dental Porcelain. The Science of Dental Ceramics, Quintessence 1979. p.55-63.

4. Wee AG, Monaghan P, Johnston WM. Variation in color between intended matched shade and fabricated shade of dental porcelain. J Prosthet Dent 2002; 87: 657-66.

5. O'Brien WJ, Kay KS, Boenke KM, Groh CL. Sources of colour variation on firing ceramic. Dent Mater 1991; 7: 170-73.

6. Hammad IA, Stein RS. A qualitative study for the bond and colour of ceramometals. Part II. J Prosthet Dent 1991; 65: 169-78.

7. Jorgenson MW, Goodkind RJ. Spectrophotometric study of five porcelain shades relative to the dimensions of color, porcelain thickness, and repeated firings. J Prosthet Dent 1979; 42: 96-105.

8. Mulla FA, Weiner S. Effects of temperature on colour stability of ceramic stains. J Prosthet Dent 1991; 65: 507-12.

9. Seghi RR, Johnston WM, O'Brien WJ. Spectrophotometric analysis of color differences between ceramic systems. J Prosthet Dent 1986; 56: 35-40.

10.Anusavice KJ. Dental ceramics. In: Phillips' Science of Dental Materials, ed 10. WB Saunders, 1996. p.595-6.

11.Douglas RD, Przybylska M. Predicting ceramic thickness required for dental shade matches. J Prosthet Dent 1991; 65: 351-6.

12.Judd DB, Wyszecki G. Color in business science and industry. 3rd edition. John Wiley; 1975. p.10522.

13. Lund PS, Piotrowski TJ. Colour changes of ceramic surface colorants resulting from firing. Int $\mathrm{J}$ Prosthodont 1992; 5: 22-7.

14.Johnston WM, Kao EC. Assessment of appearance match by visual observation and clinical colorimetry. J Dent Res 1989; 68: 819-22.

15. Ruyter IE, Nilner K, Moller B. Color stability of dental composite resin materials for crown and bridge veneers. Dent Mater 1987; 3: 246-51.

16. Shokry TE, Shen C, Elhosary MM, Elkhodary AM. Effect of core and veneer thicknesses on the color parameters of two all-ceramic systems. J Prosthet Dent 2006; 95: 124-9.

17. Jalali H, Alizadeh ES, Sadighpour L, Shabestari GO, Fard MJ. The effect of background and ceramic thickness on the color of an all-ceramic restorative system. J Calif Dent Assoc 2010; 38: 179-86.
18.Seghi RR, Hewlett ER, Kim J. Visual and instrumental colorimetric assessments of small color differences on translucent dental porcelain. J Dent Res 1989; 68: 1760-4.

19. Yap AU, Sim CP, Loh WL, Teo JH. Human-eye versus computerized color matching. Oper Dent. 1999; 24: 358-63.

20. Chu S, Devigus A, Mieleszko A., Fundamentals of Color. Quintessence Publishing; 2004. p.1-17.

21. Knispel G. Factors affecting the process of color matching restorative materials to natural teeth. Quintessence Int 1991; 22: 525-31.

22.Crispin BJ, Seghi RR, Globe H. Effect of different metal ceramic alloys on the color of opaque and dentin porcelain. J Prosthet Dent 1991; 65: 351-6.

23. Seghi RR, Daher T, Caputo A. Relative flexural strength of dental restorative ceramics. Dent Mater. 1990; 6: 181-4.

24.Primus CM, Chu CC, Shelby JE, Buldrini E, Heckle CE. Opalescence of dental porcelain enamels. Quintessence Int 2002; 33: 439-49.

25.Doğan $A$, Yüzügüllü $B$. Renk seçiminde güncel teknolojik gelişmeler [Recent technological developments in color selection]. Atatürk Üniv Diş Hek Fak Derg 2011; 4: 65-72.

26. Van der Burgt TP, ten Bosch JJ, Borsboom PC, Kortsmit WJ. A comparison of new and conventional methods for quantification of tooth color. J Prosthet Dent 1990; 63: 155-62.

27. Bolt RA, Bosch JJ, Coops JC. Influence of window size in small-window colour measurement, particularly of teeth. Phys Med Biol 1994; 39: 1133-42.

28. Yilmaz K, Ozkan P. Profilometer evaluation of the effect of various polishing methods on the surface roughness in dental ceramics of different structuressubjected to repeated firings. Quintessence Int 2010; 41: e125-31.

\section{Yazışma Adresi:}

İlkin TUNCEL

Bezmialem Vakıf Üniversitesi

Diş Hekimliği Fakültesi

Protetik Diş Tedavisi AD

34093, Fatih, İstanbul, Türkiye

Tel : +902124531700

Faks : +902125230876

E-mail: ilkint@hotmail.com 